\title{
Impact of omega-3 fatty acids on evolution of carbon tetrachloride- (CCI4) induced liver cirrhosis in mice : A histological and immunohistochemical study
}

\author{
Original \\ Article \\ Eman E. Abu-Dief ${ }^{1}$, Doha S. Mohammed ${ }^{1}$, Nesreen G. Abd El-Haliem ${ }^{1}$, Sherine A. \\ Mohammed ${ }^{1}$ and Ashraf M. El-Badry ${ }^{2}$
}

${ }^{1}$ Department of Histology, ${ }^{2}$ Department of Surgery, Faculty of Medicine, Sohag University, Sohag, Egypt

\begin{abstract}
Introduction: Cirrhosis is the end stage of any chronic liver disease. It is characterized by diffuse fibrosis with disturbed hepatic architecture. Omega-3 polyunsaturated fatty acids are common antioxidant, anti-inflammatory and anti-fibrotic agents

Aim: This study was conducted to investigate the potential effects of omega-3 fatty acids on experimentally induced cirrhosis.

Materials and Methods: 60 animals were divided into three groups: Group I (control): 10 animals, group II: 25 animals treated with carbon tetrachloride (CCl4), and Group III : 25 animals treated with CCl4 then with omega-3 concomitant with $\mathrm{CCl} 4$ for additional two weeks after induction of cirrhosis. Body weight and liver weight coefficient were measured. Liver samples were taken for histological and immunohistochemical studies.

Results: Omega-3 fatty acids treatment attenuated the $\mathrm{CCl} 4$ induced cirrhosis. Histological studies revealed that it decreased the stage of fibrosis, and the grade of the necroinflammatory changes. Immunohistochemical studies demonstrated that apoptotic changes diminished in cirrhotic livers after treatment with omega-3 fatty acids with a significant decrease in the cleaved caspase- 3 index. Furthermore, there was a significant decrease in the number of macrophages, and hepatic stellate cells activation.

Conclusion: Our results suggest that omega-3 fatty acids have an anti-inflammatory and anti-fibrotic effects on CCl4 induced liver cirrhosis in mice.
\end{abstract}

Revised: 02 November 2017, Accepted: 14 November 2017

Key Words: Apoptosis, $\alpha$-SMA, fibrosis, liver, omega-3, TIMP-1.

Corresponding Author: Sherine A. Mohammed, Department of Histology, Faculty of Medicine, Sohag University, Sohag Egypt, Tel.: 00201120301020, E-mail: Loua.sherine@yahoo.com.

ISSN: 1110-0559, Vol. 41, No.1

\section{INTRODUCTION}

Liver is the major organ responsible for metabolism and detoxification of many endogenous and exogenous toxins. Therefore, there is high prevalence of major liver diseases such as chronic hepatitis, fibrosis, cirrhosis, or hepatic carcinoma ${ }^{[1]}$. WHO updates $^{[2]}$ revealed that an estimated 325 million people worldwide have chronic hepatitis $\mathrm{B}$ or $\mathrm{C}$ virus infection. In Egypt, Hepatitis $\mathrm{C}$ virus $(\mathrm{HCV})$ infection is endemic with the highest prevalence in the world ${ }^{[3]}$. Liver cirrhosis is the end result of chronic liver diseases with no effective strategy to treat.

Cirrhosis occurs on top of prolonged fibrosis with disturbed hepatic architecture and formation of regenerative nodules ${ }^{[1]}$. Animal models are used to study the mechanism of liver fibrosis and cirrhosis. They can facilitate the study of interaction of hepatocytes, hepatic stellate cells (HSCs), and immune cells during fibrogenesis ${ }^{[4]}$. HSCs, also called Ito cells, fat storing cells, or lipocytes, are the key fibrogenic cells in liver cirrhosis. Normally HSCs are branched cells present in the perisinusoidal space. Activated HSCs acquire a myofibroblastic phenotype and deposit large quantities of extracellular matrix components within the liver and migrate to the site of collagen deposition. Apoptosis of hepatocytes activates $\mathrm{HSCs}^{[5]}$. Furthermore, inflammation leads to activation, recruitment and migration of Kupffer cells which in turn activate $\mathrm{HSCs}^{[4]}$.

Omega-3 polyunsaturated fatty acids, including eicosapentaenoic acid, docosahexaenoic acid and alphalinoleic acid, exist in large amounts in fish and fish oils $^{[6]}$. Experimental studies have demonstrated beneficial effects of omega-3 fatty acids on cancer ${ }^{[7]}$, cardio vascular diseases ${ }^{[8]}$, and nervous system disorders ${ }^{[9]}$. Hypolipidemic effects of omega-3 fatty acids dietary consumption were reported in nonalcoholic fatty liver diseases ${ }^{[10]}$ as they have antioxidant properties acting as a free radical scavenger ${ }^{[11]}$. Moreover, they have inhibitory effects on the main profibrotic agent; transforming growth factor $\beta^{[12]}$ and proinflammatory cytokines ${ }^{[6]}$. 


\section{MATERIALS AND METHODS}

\section{Experimental design}

Sixty adult male Balb/c mice; about 2 months old with average weight $35 \mathrm{gm}$, were purchased from Assiut Experimental Animal Facility, Assiut University. Animals were housed in Sohag University animal house with free access to water and chow. They were acclimatized to this environment for 5 days prior to the experiment. All procedures used in this experiment were approved with the local Ethics Committee of Sohag University, Faculty of Medicine.

Animals were randomly divided into three groups: Group I: 10 animals subdivided in two groups:

-Group IA (control): 5 animals were injected subcutaneously with the vehicle; sunflower oil in a dose of $1 \mathrm{ml} / \mathrm{Kg}$ twice weekly for 16 weeks.

-Group IB: 5 animals were injected subcutaneously with the vehicle; sunflower oil in a dose of $1 \mathrm{ml} / \mathrm{Kg}$ twice weekly for 16 weeks then injected only with omega-3 in a dose of $0.4 \mathrm{~g} / \mathrm{Kg}$ daily for another two weeks.

Group II included 25 animals were subcutaneously injected with $50 \%$ carbon tetrachloride $(\mathrm{CCl} 4)$ diluted in sunflower oil, Sigma-Aldrich Company, Germany) in a dose of $1 \mathrm{ml} / \mathrm{Kg}$, twice weekly for 16 weeks for induction of cirrhosis ${ }^{[13]}$.

Group III 25 animals treated with CCl4 for 16 weeks in the aforementioned dose for induction of cirrhosis, then with daily intraperitoneal injection of omega-3 (Fresenius Company, Germany) in a dose of $0.4 \mathrm{~g} / \mathrm{kg}^{[11]}$ concomitant with $\mathrm{CCl} 4$ for additional two weeks after induction of cirrhosis (collectively 18 weeks CCl4 ).Body weight and liver weight coefficient

At the end of the experiment body weight was measured in all groups. Thereafter, all the animals anaesthetized by intraperitoneal injection of ketamine in a dose of $100 \mathrm{mg} /$ $\mathrm{kg}$ body weight ${ }^{[13]}$ and sacrificed. The liver was excised and weighed accurately. The coefficients of the liver to body weight were calculated as the ratio of liver (wet weight $\mathrm{mg}$ ) to body weight $(\mathrm{g})$ in all groups ${ }^{[14]}$.

\section{Histological studies}

Liver samples were obtained from the right lobes in all examined animals, and immediately fixed in a $10 \%$ formalin solution, embedded in paraffin blocks, sliced into $5 \mu \mathrm{m}$ thickness, mounted onto glass slides, and stained with hematoxylin and eosin, and Masson trichrome stain according to Bancroft et al. ${ }^{[15]}$.

We used METAVIR scoring system for the evaluation of both necroinflammatory changes and fibrosis. The necroinflammatory changes grading is called histological activity index (HAI) and includes two parameters; piecemeal necrosis with or without bridging necrosis, and focal intralobular necrosis. HAI is scored according to the extent of cellular degeneration from 0 to 4 ; 0 : none, 1 : mild, 2: moderate, and 4: severe. The staging of fibrosis is scored from F0 to F4; F0: no fibrosis; F1: fibrotic changes confined to the portal tracts (portal fibrosis), with only mild portal expansion; F2: formation of incomplete fibrous septa; F3: formation of portal-to-portal fibrous septa (septal or bridging fibrosis); F4: complete cirrhosis ${ }^{[16]}$.

\section{Immunohistochemical studies}

Formalin fixed paraffin embedded $4 \mu \mathrm{m}$ thick sections were deparaffinized in xylene, rehydrated in descending grades of alcohols, and then treated with 3\% hydrogen peroxide for 10 minutes. Antigen retrieval was done by putting slides in a microwave oven in citrate buffer solution ( $\mathrm{pH}$ 6.0) for all used antibodies except for $\alpha$-SMA, EDTA ( $\mathrm{pH}$ 9.0) was used. The sections were incubated with the primary antibody at $4^{\circ} \mathrm{C}$ for $18-20 \mathrm{~h}$. Labeled streptavidin- biotin method was performed using anti-polyvalent HRD/DAP plus labvision detection system. The sections were incubated with the primary antibody at $4{ }^{\circ} \mathrm{C}$ for $18-20 \mathrm{~h}$. Primary antibodies; Mouse monoclonal PCNA antibody, Ab-1, pc10,1 400, for detection of cell proliferation), rabbit polyclonal cleaved caspase 3 antibody (Ab-4, RB-1197-p0,1/100, for detection of apoptosis), mouse monoclonal $\alpha$ - SMA antibody (Ab-19, 1A4, MS-113-p0, 1/100, for detection of HSCs) and rabbit polyclonal anti CD68 antibody (E13920, $1 / 100$, for detection of macrophages) were purchased from Thermo scientific, Neomarks, Fremont, USA. Rabbit polyclonal Anti TIMP-1 antibody (E3360, 1/100, for detection of decreased collagen degradation) and rabbit monoclonal Anti CD31 antibody (SP38, 1/100m, for detection of continuous endothelial lining of blood vessels) were purchased Springbio-company, Pleasanton. The sections were finally counterstained with hematoxylin. Negative control slides were done with omission of the primary antibodies using non immunized goat sera ${ }^{[13]}$.

Table (1) summarizes the positive control, and the site of expression for each antibody used in the study.

\section{Morphometric studies}

The light microscope Leica ICC50 Wetzlar (Germany) at the Histology Department, Faculty of Medicine, Sohag University was used, ten high power fields $(\mathrm{x} 400)$ for each case in all groups ${ }^{[14]}$. Analysis was done using Image $\mathrm{J}$ software (version 1.46r) as follows:

1 - The percentage areas of collagen fibers and of $\alpha$-SMA, TIMP-1 and CD31 expression.

2- The number of PCNA positive nuclei and the number of cleaved caspase- 3 positive cells, labeling index for each of them was calculated as: (the number of positive cells/ number of total cells counted in the field) $\mathrm{x} 100$. 3- The number of CD68 positive cells.

\section{Statistical analysis}

Paired sample Student t-test with a statistical significance of $P<0.05$ was used to analyze the data by 
using SPSS program (version 16.00; SPSS Inc., Chicago, Illinois, USA). Data were expressed as mean \pm standard error (SEM).

\section{RESULTS}

\section{Survival rate}

Ten deaths out of 50 animals $(20 \%)$ were reported during the induction of cirrhosis.

\section{Gross morphology}

In group IA, IB the liver had glistening smooth surface and soft texture. In group II, it was increased in size and had nodular surface and hard texture. However, in group III, the liver showed slight nodularity (Fig. 1).

\section{Animal body weight}

The animal body weight and liver weight coefficient in group IB had non-significant changes as compared to that of group IA. In group II, the animal body weight was significantly decreased and the liver weight coefficient was significantly increased as compared to that in group IA. However, in group III the animal body weight was significantly increased and the liver weight coefficient was significantly decreased as compared to that in group II (histogram 1 and table 2).

\section{Histological results}

Group IA, IB showed similar results. In the liver sections stained with H\&E from group IA (control) mice, hepatocyte plates in the hepatic lobules were radiating from the central vein to the periphery and the blood sinusoids in between. The hepatocytes had acidophilic vacuolated cytoplasm with vesicular nucleus and some of them were binucleated (HAI grade 0) (Fig. 2a). Group II showed complete loss of lobular architecture into cirrhotic nodules with congestion and dilatation in the portal veins. Apparent narrowing of blood sinusoids was observed with appearance of new blood vessel within the fibrous septa. Inflammatory cellular infiltrations were found in the portal areas and within the fibrous septa. Ballooning degeneration of many hepatocytes was observed, some of them had pale acidophilic vacuolated cytoplasm. Other hepatocytes had highly acidophilic cytoplasm and pyknotic nuclei (HAI stage 3) (Fig. 2b). In group III, liver sections showed marked improvement in the hepatic architecture disturbance, less congestion in central and portal veins, and less narrowed sinusoid as compared to group II. Newly formed blood vessels were less frequently seen. Cellular infiltrations were observed around the central veins and in the portal areas. Hepatocytes appeared with acidophilic vacuolated cytoplasm. Most of hepatocytes had vesicular nucleus and some cells were binucleated. Inflammatory infiltrations were seen (HAI stage 1) (Fig. 2c).

With Masson trichrome stain, the examined liver sections of group IA showed few collagen fibers only around the central veins and in the portal areas (F0) (Fig. $2 \mathrm{~d})$. In group II, collagen fibers significantly increased as compared to that in group IA; numerous collagen fibers appeared in the portal areas with formation of fibrous septa completely surrounding the hepatic lobules and the cirrhotic nodules (F4). Some collagen fibers appeared in the perisinusoidal spaces (Fig. 2e). In group III, collagen fibers significantly decreased as compared to that in group II; few collagen fibers appeared around the central veins and some collagen fibers in the portal areas with fibrous septa partially surrounding the hepatic lobules (Fig. 2f). The mean percentage areas of collagen fibers in all groups are summarized in histogram 2 and table 3.

\section{Immunohistochemical results}

Group IB had non-significant changes as compared to that of group IA in all immunohisochemical parameters.

\section{Cleaved caspase-3}

The cleaved caspase-3 index in group II was significantly higher (Fig. 3b) as compared to that in group IA (Fig. 3a). In group III, it decreased significantly as compared to that in group II (Fig. 3c).

\section{Proliferating cell nuclear antigen (PCNA)}

The PCNA index in group II significantly decreased (Fig. 3e) as compared to that in group IA (Fig. 3d). In group III, it increased significantly as compared to that in group II (Fig. 3f).

The mean indices of cleaved caspase- 3 and PCNA in all groups are summarized in histogram 3 and table 4 .

\section{$\alpha$-smooth muscle actin ( $\alpha-S M A)$}

In group IA, the examined liver sections showed positive immunostaining of $\alpha$ - SMA in the smooth muscle fibers of the tunica media in the central vein and the blood vessels in the portal area (Fig. 4a). In group II, its expression was significantly higher as compared to that in group IA; being demonstrated in spindle shaped cells surrounding the sinusoidal wall, and within the fibrous septa (Fig. 4b). In group III, it decreased significantly as compared to that in group II. It was expressed in few spindle shaped cells within incomplete fibrous septa (Fig. 4c).

\section{Tissue inhibitor of metalloproteases(TIMP-1)}

In group IA, the examined liver sections showed positive immunostaining in only few kupffer cells (Fig. 4d). In group II, its expression was significantly higher as compared to that in group IA; being positive in most of the hepatocytes and in some Kupffer cells (Fig. 4e). In group III, it was significantly decreased as compared to that in group II; positivity was seen in only few hepatocytes and in few Kupffer cells (Fig. 4f).

The mean percentage areas of $\alpha$ - SMA and TIMP-1 expression in all groups are summarized in histogram 4 and table 5 . 


\section{CD68}

In group II, the number of CD68 positive Kupffer cells was significantly decreased, while the number of connective tissue CD68 positive cells was significantly higher (Fig. 5b) as compared to that in group IA (Fig. 5a).

In group III, its expression significantly increased in Kupffer cells, and decreased in connective tissue as compared to that in group II. However, connective tissue positive macrophages number was still significantly elevated as compared to that in group IA (Fig. 5c). The mean numbers of CD68 positive Kupffer cells in all groups are summarized in histogram 5 and table 6.

\section{CD31}

In group IA, positive immunostaining of CD31 was seen in the endothelial cells lining central veins and portal area blood vessels (Fig. 6a). In group II, CD31 expression significantly increased as compared to that in group IA; appeared in the endothelial cells lining the sinusoids, in addition to that lining the new blood vessels within fibrous septa (Fig. 6b). In group III, it decreased significantly as compared to that in group II, the immunopositivity disappeared from the endothelial cells lining most of the sinusoids (Fig. 6c). The mean percentage areas of CD31 expression in all groups are summarized in histogram 6 and table 7.

Table 1: Antibodies Antibodies used in the immunohistochemical studies

\begin{tabular}{lccc}
\hline Antibody & Dilution & Positive control & $\begin{array}{c}\text { Site of expression } \\
\text { (brownish staining) }\end{array}$ \\
\hline PCNA & $1: 400$ & Skin & Cyclear \\
Cleaved caspase 3 & $1: 100$ & Tonsil & Cytoplasmic \\
$\alpha$-SMA & $1: 200$ & Small intestine & Cytoplasmic \\
TIMP-1 & $1: 100$ & Colon cancer & Membranous \\
CD31 & $1: 100$ & Tonsil & Cytoplasmic \\
\hline
\end{tabular}

Table 2: animal Animal body weight and liver weight coefficient

$\begin{array}{lcc}\text { Group } & \text { Body weight BW }(\mathrm{g})(\text { mean } \pm \text { SEM) } & \begin{array}{c}\text { Liver weight coefficient } \\ (\text { mean } \pm \text { SEM })\end{array} \\ \text { Group IA } & 38.98( \pm 0.7) & 5.06( \pm 0.01) \\ \text { Group IB } & 39.52( \pm 0.5) \mathrm{NS} & 5.12( \pm 0.04), \mathrm{NS} \\ \text { Group II } & 24.02( \pm 0.3) * & 10.15( \pm 0.09)^{*} \\ \text { Group III } & 33.88( \pm 0.4) \#, \mathrm{NS} & 6.66( \pm 0.04) \#, \mathrm{NS}\end{array}$

*Significant as compared to group IA $(P$ value $<0.05)$

\#Significant as compared to group II $(P$ value $<0.05)$

NS: Non significant as compared to group IA 
Table 3: The mean percentage area of collagen fibers

\begin{tabular}{lc}
\hline Group & $\begin{array}{c}\text { Collagen fibers percentage } \\
\text { area. mean }( \pm \text { SEM })\end{array}$ \\
\hline Group IA & $0.73 \%( \pm 0.05)$ \\
Group IB & $0.79 \%( \pm 0.06) \mathrm{NS}$ \\
Group II & $13.4 \%(1.34)^{*}$ \\
Group III & $3.39 \%( \pm 1.58) * \#$ \\
\hline
\end{tabular}

*Significant as compared to group IA ( $P$ value $<0.05)$,

\#Significant as compared to group II ( $P$ value $<0.05)$.

NS: Non significant as compared to group IA

Table 4: The mean percentage area of cleaved caspase- 3 , and PCNA index

\begin{tabular}{lcc}
\hline Group & $\begin{array}{c}\text { Cleaved caspase } \\
3 \text { index (mean } \\
\pm \text { SEM })\end{array}$ & $\begin{array}{c}\text { PCNA index } \\
(\text { mean } \pm \text { SEM) }\end{array}$ \\
\hline Group IA & $01.1 \%( \pm 0.1)$ & $2 \%( \pm 0.1)$ \\
Group IB & $0.8 \%( \pm 0.1) \mathrm{NS}$ & $01.8 \%( \pm 0.1) \mathrm{NS}$ \\
Group II & $17.6 \%( \pm 2.0)^{*}$ & $1.1 \%( \pm 0.6)^{*}$ \\
Group III & $4.5 \%( \pm 0.6)^{* \#}$ & $25 \%( \pm 1.1)^{*} \#$ \\
\hline
\end{tabular}

*Significant as compared to group IA ( $P$ value $<0.05)$.

\#Significant as compared to group II ( $P$ value $<0.05)$.

NS: Non significant as compared to group IA

Table 5: The mean percentage area of $\alpha$-smooth muscle actin, and TIMP-1 expression

\begin{tabular}{lcc}
\hline Group & $\begin{array}{c}\alpha \text {-smooth muscle } \\
\text { actin expression } \\
\text { percentage area } \\
(\text { mean } \pm \text { SEM })\end{array}$ & $\begin{array}{c}\text { TIMP-1 expression } \\
\text { percentage area } \\
(\text { mean } \pm \text { SEM })\end{array}$ \\
\hline Group IA & $0.8 \%( \pm 0.1)$ & $0.4 \%( \pm 0.03)$ \\
GroupIB & $0.7 \%( \pm 0.1) \mathrm{NS}$ & $0.5 \%( \pm 0.02) \mathrm{NS}$ \\
Group II & $7.7 \%( \pm 2.00) *$ & $28.16 \%( \pm 0.2)^{*}$ \\
GroupIII & $2.1 \%( \pm 0.66) \# \mathrm{NS}$ & $6.5 \%( \pm 0.3)^{*} \#$ \\
\hline
\end{tabular}

*Significant as compared to group IA ( $P$ value $<0.05)$, \#Significant as compared to group II ( $P$ value $<0.05)$ NS: Non-significant as compared to group IA
Table 6: The mean of CD68 expression in connective tissue macrophages

\begin{tabular}{lcc}
\hline Group & $\begin{array}{c}\text { CD68 expression } \\
\text { in Kupffer cells } \\
(\text { mean } \pm \text { SEM })\end{array}$ & $\begin{array}{c}\text { CD68 expression } \\
\text { in connective } \\
\text { tissue macrophages } \\
(\text { mean } \pm \text { SEM })\end{array}$ \\
\hline Group IA & $12( \pm 0.1)$ & $0.3( \pm 0.08)$ \\
Group IB & $13( \pm 0.1) \mathrm{NS}$ & $0.4( \pm 0.08) \mathrm{NS}$ \\
Group II & $1.8( \pm 0.3)^{*}$ & $9( \pm 0.3)^{*}$ \\
Group III & $21( \pm 0.6)^{*}$ & $6.3( \pm 0.1)^{*}$ \\
\hline
\end{tabular}

*Significant as compared to group IA $(P$ value $<0.05)$, \#Significant as compared to group II ( $P$ value $<0.05)$.

NS: Non significant compared to group IA

Table (7): The mean percentage area of CD31 expression

\begin{tabular}{lc}
\hline Group & $\begin{array}{c}\text { Percentage area of CD31 } \\
\text { expression }(\text { mean } \pm \text { SEM })\end{array}$ \\
\hline Group IA & $0.4 \%( \pm 0.1)$ \\
Group IB & $0.3 \%( \pm 0.1) \mathrm{NS}$ \\
Group II & $4.4 \%( \pm 0.6)^{*}$ \\
Group III & $1.2 \%( \pm 0.6)^{* \#}$ \\
\hline
\end{tabular}

*Significant as compared to group IA.

\#Significant as compared to group II.

NS: Non significant as compared to group IA.

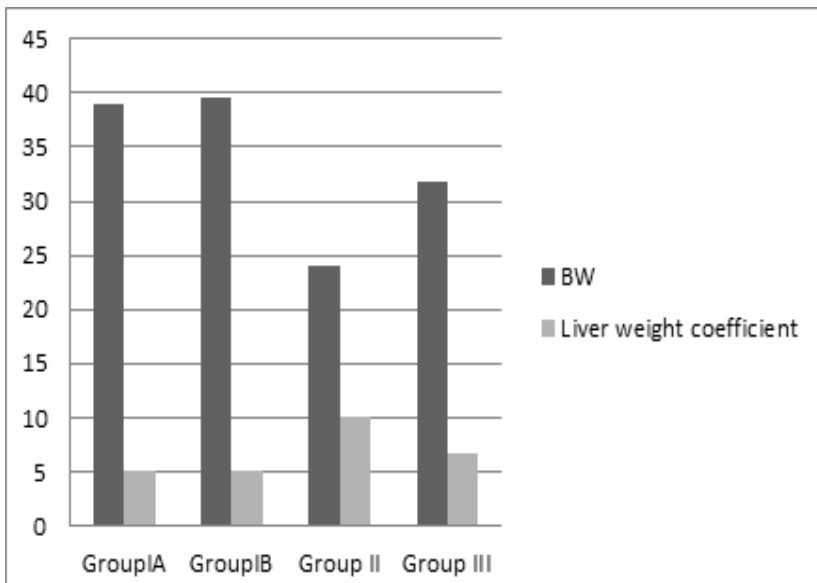

Histogram 1: Animal body weight(BW) and liver weight coefficient 


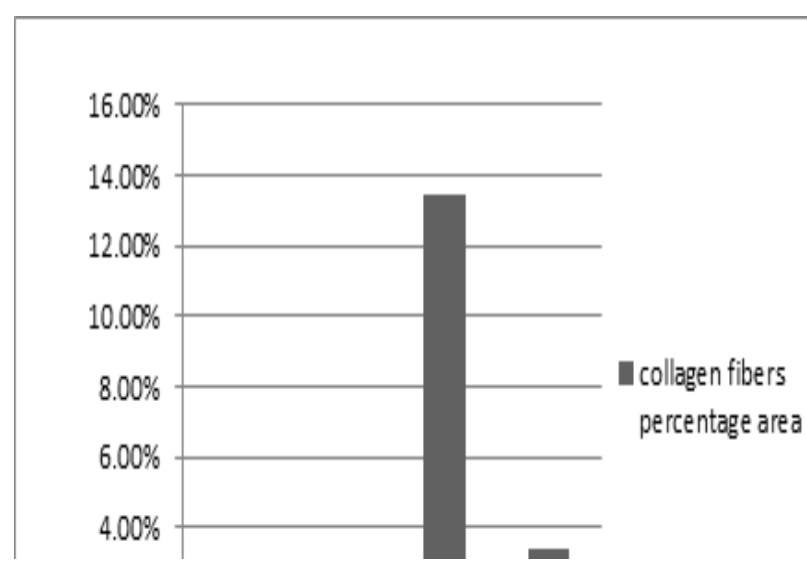

Histogram 2: The mean percentage area of collagen fibers.

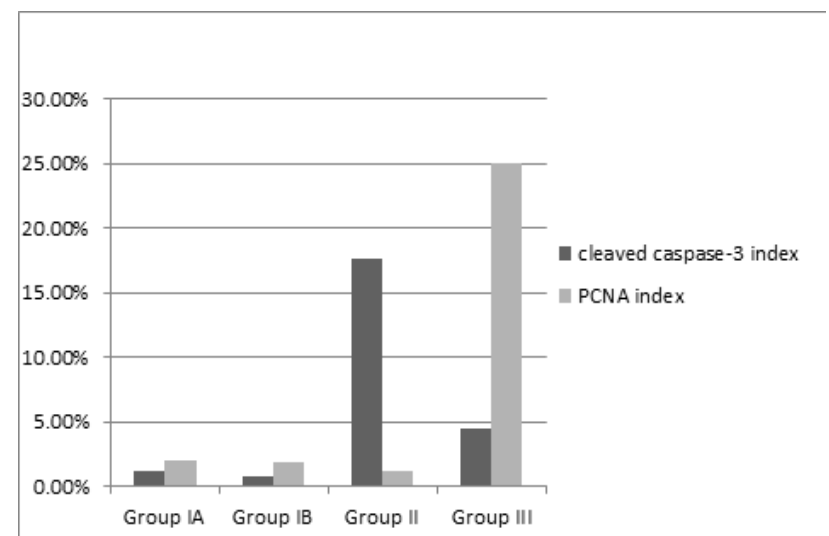

Histogram 3: The mean index of cleaved caspase -3 and PCNA

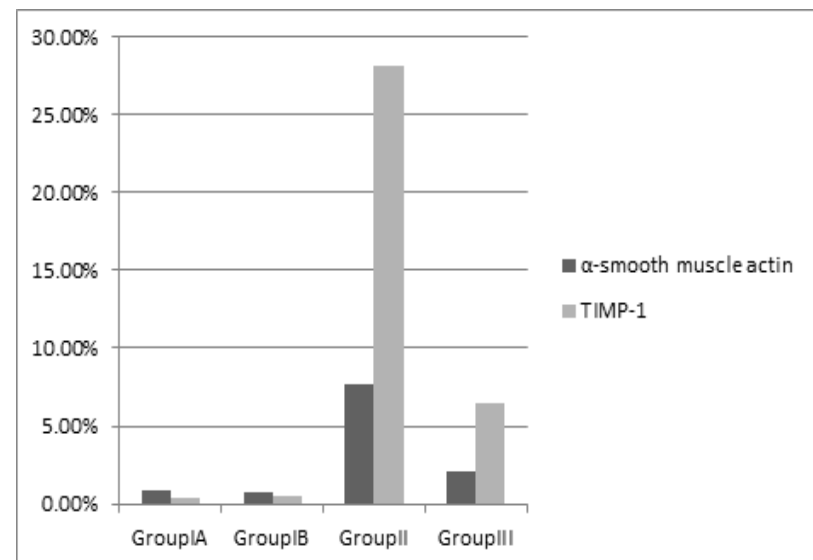

Histogram 4: The mean percentage area of $\alpha$-smooth muscle actin and TIMP-1 expression.

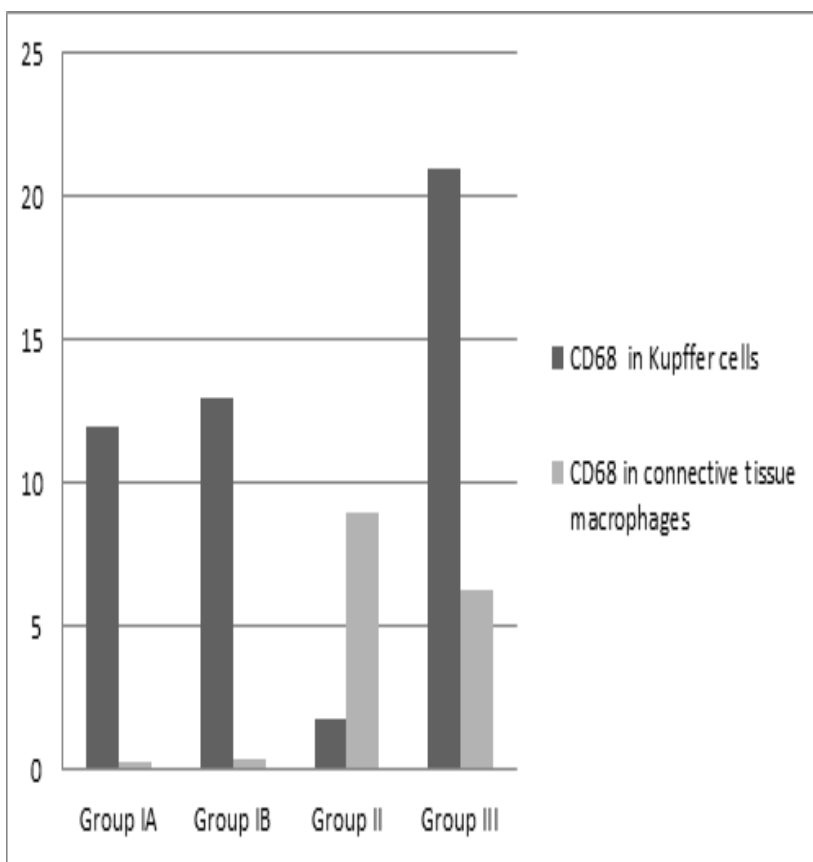

Histogram 5: The mean of CD68 expression

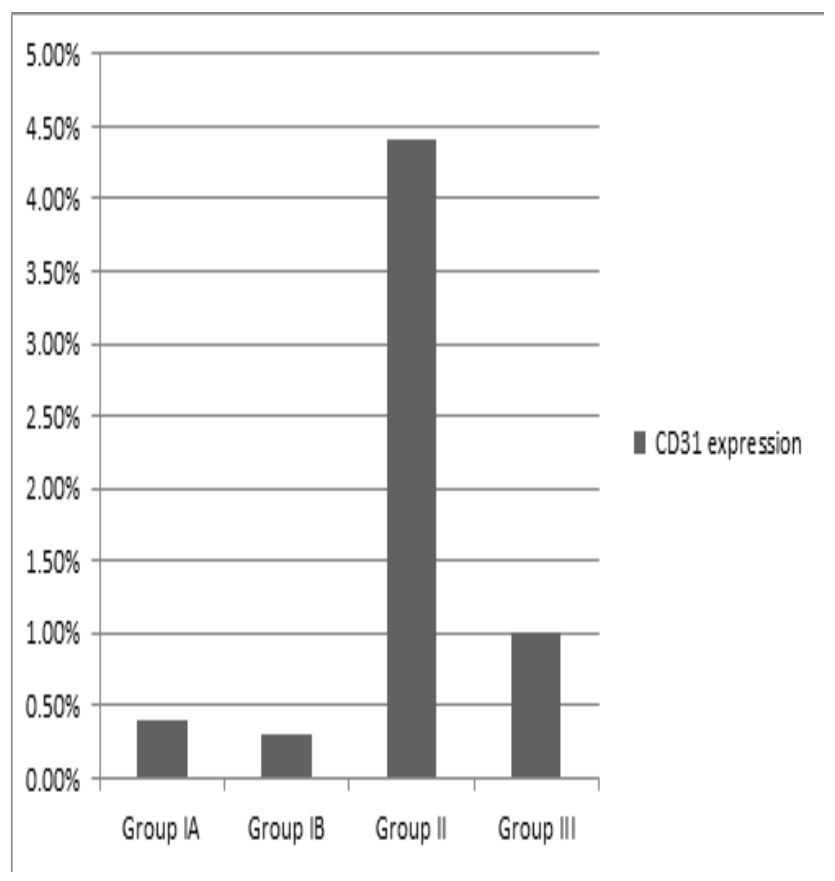

Histogram 6: The mean percentage area of CD31 expression 


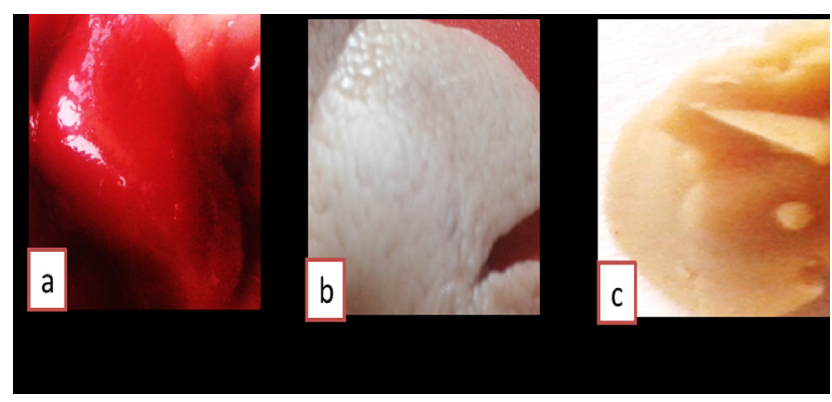

Fig. 1: Photomicrographs showing macroscopic picture of liver lobes from animals of: (a) group IA, (b) group II, (c) group III. (d) Body weight and liver weight coefficient
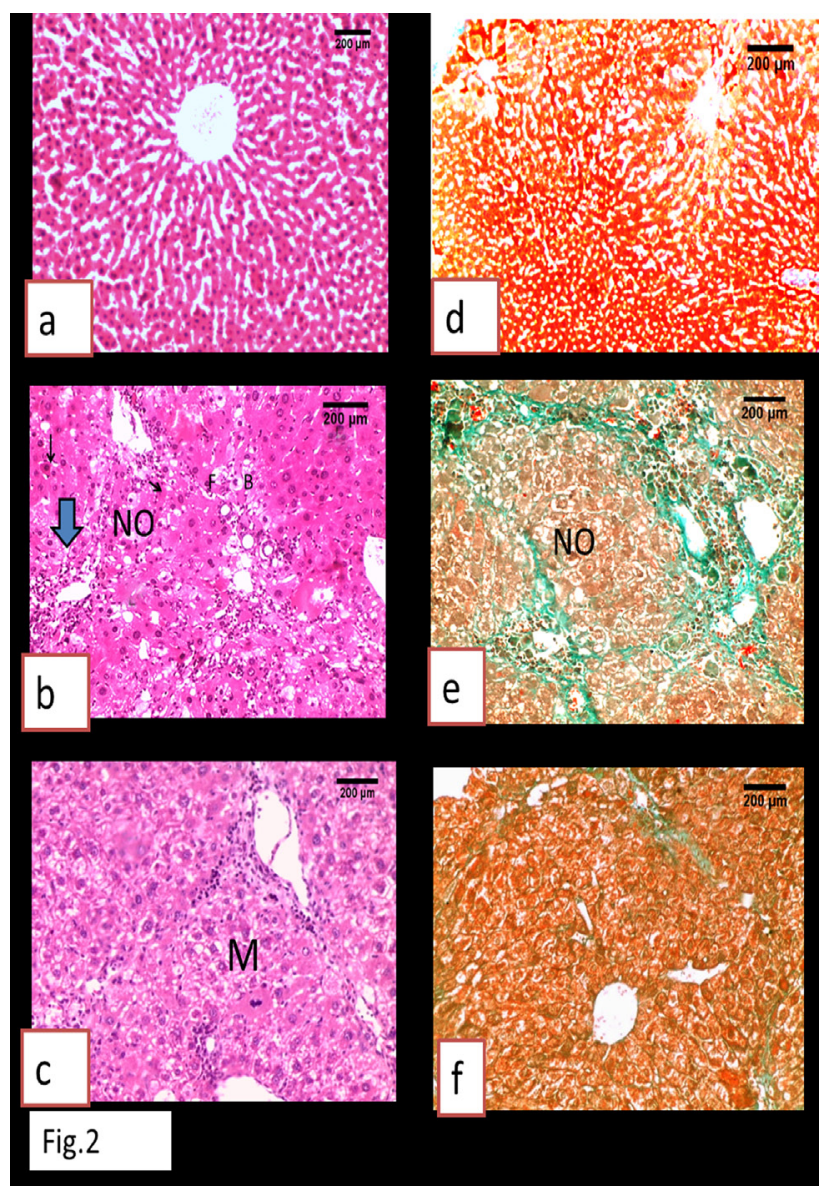

Fig. 2: Photomicrographs of liver sections from animals of group IA $(a, d)$. group II $(b, e)$. group III $(c, f)$. H\&E $(a, b, c)$. Masson's trichrome stain (d,e,f).(a) control liver with normal architecture and hepatocytes radiating from the central vein with acidophilic cytoplasm and central roundedvesicular nucleus. (b) loss of architecture with formation of cirrhotic nodules (NO), cell infiltration and degenerative changes in the form of apoptotic hepatocytes (thin arrow), vacuolated hepatocytes (thick arrow), ballooning (B) and fatty degeneration (F) in group II. (c) hepatocytes more or less normal with some cellular infiltration and mitotic figure in the metaphase (M) in group III. (d) few collagen fibers in the portal area and around the central vein in the control. (e) thick fibrous septa completely surround the cirrhotic nodule (NO). (f) incomplete septa (x200, scale bar=200um).

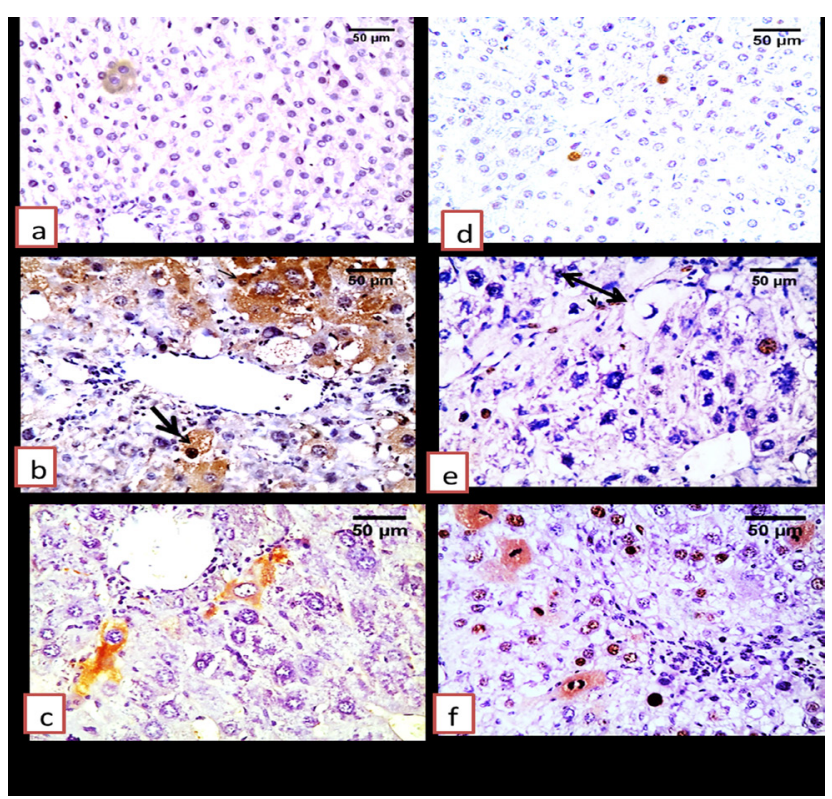

Fig. 3: Photomicrographs of liver sections from an animal of group IA (a, d), group II (b, e), group III (c,f). Cleaved caspase-3 antibody (a, b, c). PCNA antibody (d, e, f). (a) caspase-3 positivity in few hepatocytes(b) increased caspase-3 expression in groupII. Nuclear caspase-3 immunopositivity (arrow). (c) decreased caspase-3 expression in groupIII compared to groupII. (f) increased PCNA expression in hepatocytes in groupIII. Note PCNA cytoplasmic immunostaining in mitotic dividing cells. PCNA positive spindle shaped cells within the septa (double headed arrow). (x400, scale bar=50um ).

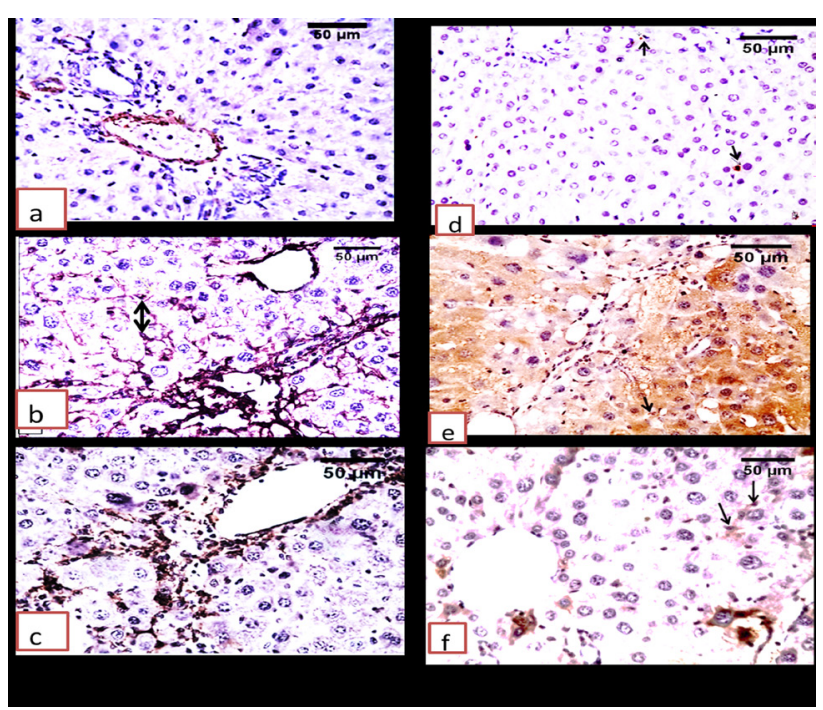

Fig. 4: Photomicrographs of liver sections from an animal of group IA $(a, d)$. group II $(b, e)$. group III $(c, f) . \alpha$-SMA antibody $(a . b, c)$. TIMP-1 antibody (d,e,f). (a) $\alpha$-SMA positivity only in blood vessels of the portal area (b) $\alpha$-SMA positivity in perisinusoidal spaces and within fibrous septa in groupII. (c) within fibrous septa in groupIII. $\alpha$-SMA positive cells within the perisinusoidal space(double headed arrow), (a) TIMP-1 positive Kupffer cells, no positive hepatocytes (e) TIMP-1 positivity appeared in many hepatocytes in groupII. (f) TIMP-1 positivity appeared in few hepatocytes in group III. TIMP-1 positive Kupffer cells (arrow). (x400, scale bar $=50 u m)$. 


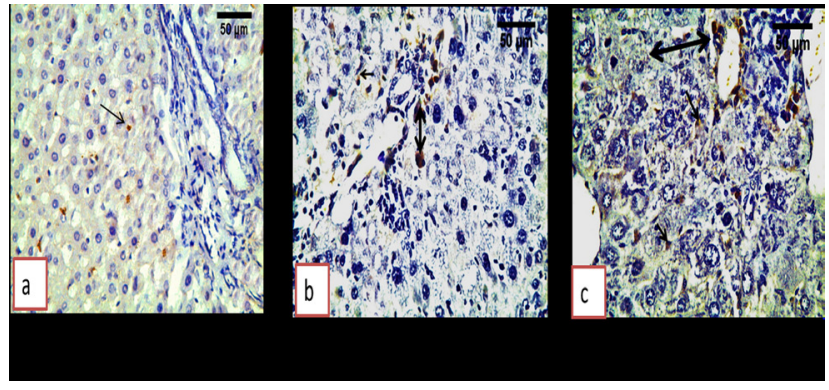

Fig. 5: Photomicrographs of liver sections from an animal of groupIA (a). groupII(b). groupIII(c). (a) kupffer cells are positive with no connective tissue macrophages .(b) macrophages increased in connective tissue and Kupffer cells decreased in groupII..(C) macrophages decreased in connective tissue and Kupffer cells increased in groupIII. Kupffer cells (arrow). Connective tissue macrophages (double headed arrow) (CD68 antibody) (X400, scale bar=50um).

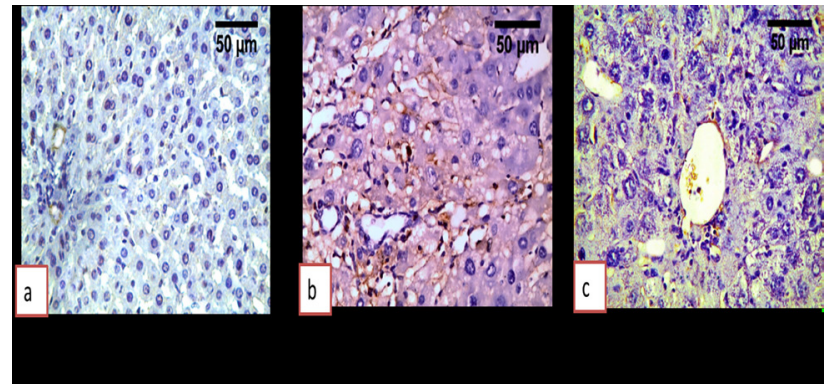

Fig. 6: Photomicrographs of liver sections from an animal of groupIA (a). groupII (b). groupIII (c) (CD31antibody).(a) positivity only in endothelial lining of blood vessels in the portal area (b) Sinusoidal endothelium positivity; capillarized sinusoids. (c) Positivity only in endothelial lining of large blood vessels, disappeared in most of the sinusoids. (x400, scale bar=50um ).

\section{DISCUSSION}

Liver cirrhosis is the final outcome of chronic liver diseases. It represents a worldwide challenge, because no effective treatment is present for it up till now except liver transplantation. There is an urgent need to find an available and effective treatment for liver cirrhosis. Omega-3 polyunsaturated fatty acids are strong antioxidant, antiinflammatory, and antifibrotic agents ${ }^{[12]}$, which can be used for treatment of liver cirrhosis.

CCl4 induced liver cirrhosis is a good model to study antifibrotic drugs. The current study revealed that $\mathrm{CCl} 4$ injection for 16 weeks caused a significant decrease in the animals' weights and increase in liver coefficient as compared to the control with macroscopic nodular surface of the liver. The histopathological changes were in the form of ballooning degeneration and vacuolation extending in most of the nodule $(\mathrm{HAI}=3)$ consistent withprevious studies ${ }^{[17]}$. Most of the hepatocytes exhibited apoptotic changes which were confirmed by immunohistochemistry. There was significant increase in cleaved caspase-3 expression in the cytoplasm of hepatocytes with nuclear staining in some of them due to translocation of the activated caspase to the nucleus after its cleavage.

Furthermore, the decrease in PCNA expression indicates decreased hepatocyte proliferation as a result of severe hepatocyte degeneration. These results are consistent with previous reports ${ }^{[18]}$. On the other hand, some studies reported increased hepatocyte proliferation and decreased apoptosis in thioacetamide model of liver cirrhosis ${ }^{[19]}$.

Collagen fibers significantly increased in group II with disturbed architecture and formation of cirrhotic nodules completely surrounded by fibrous septa (F4). Similar findings were observed in previous studies ${ }^{[20]}$. Two mechanisms contribute to liver fibrosis; increased synthesis of collagen fibers by activated HSCs and decreased degradation (21). Upon injury, HSCs transdifferentiate into myofibroblasts and express $\alpha-\mathrm{SMA}^{[13]}$. In the current study, group II animals exhibited significant increase in $\alpha$-SMA expression within the fibrous septa and in the prisinusoidal space which indicates activation and migration of HSCs. Furthermore, accumulation of the matrix due to decreased collagen degradation was indicated by a significant increase in TIMP-1, an inhibitor of matrix metalloproteases (MMPs). Similar findings were demonstrated in cirrhosis models and in human HSCs culture $^{[13,22]}$

The role of macrophages in liver fibrogenesis cannot be neglected. Inflammation stimulates Kupffer cells to produce proinflammatory and fibrogenic mediators which stimulate both hepatocyte apoptosis and HSCs activation. In the present study inflammatory cellular infiltrations were obviously seen in group II. CD68 immunohistochemical staining revealed a significant increase of connective tissue macrophages with decreased number of Kupffer cells (CD68 positive cells in between parenchymal cells) compared to the control. In agreement with Mori et al 2009 and Beljaars et al 2014, whereas macrophages were prominently present in the fibrous septa.

MacPhee et al. $1992^{[25]}$ attributed the decreased number of Kupffer's cells in the livers of cirrhotic mice to their migration along the sinusoids.

In the present study, vascular changes in $H \& E$ stained sections were prominent in group II in the form of congestion and dilatation of portal veins due to portal hypertension. Apparent sinusoidal narrowing was seen due myofibroblastic contraction and collagen deposition in the sinusoidal wall ${ }^{[13]}$. Neoangiogenesis was found within the fibrous septa confirmed by immunohistochemistry in which there was significant increase in CD31 expression. These results are in accordance with Bocca and colleagues, 201526). HSCs produce VEGF; an angiogenic growth factor upregulated by hepatic tissue hypoxia ${ }^{[13]}$. Furthermore, CD31 positive endothelial cells in hepatic sinusoids were found in group II. CD31 is a transmembrane glycoprotein only expressed in continuous endothelium. 
Capillarization of the sinusoids in which they lose their fenestrae and develop a complete basement membrane occurs in cirrhotic liver due to increased collagen synthesis by HSCs, which agree with previous studies ${ }^{[13,27]}$

Liver cirrhosis induced by $\mathrm{CCl} 4$ is reversible ${ }^{[5,20]}$. So that, we administrated omega- 3 fatty acids concomitant with $\mathrm{CCl} 4$ after cirrhosis has been developed. The present study revealed that omega-3 fatty acids administration attenuated liver cirrhosis induced by $\mathrm{CCl}$. They significantly increased body weight, and decreased liver weight coefficient as compared to that in group II. They caused a decrease in the extent of degenerative changes, HAI score decreased to 1 . Noteworthy, liver cells appeared more or less similar to the control in H\&E stained sections with frequent mitotic figures. A significant increase in PCNA expression in hepatocytes nuclei with cytoplasmic staining in cells with mitotic figures due to disruption of the nuclear envelop during cell division and translocation of the nuclear proteins to the cytoplasm. This can be explained by the antioxidant role of omega- 3 fatty acids. Oxidative stress in CCl4 leads to oxidation of membrane unsaturated fatty acids with generation of lipid peroxides which leads to tissue injury ${ }^{[28]}$. In a similar research,Uygur et al. 2014 stated that omega-3 fatty acids decreased doxorubicininduced oxidative damage and increased PCNA in rat testis. In contrast, they reduced hepatocyte proliferation induced in liver injury caused by lipopolysaccharide ${ }^{[30]}$.

In our study, omega-3 fatty acids administration decreased the $\mathrm{CCl} 4$ induced apoptotic cell death. This was demonstrated by the significantly decreased immunoexpression of cleaved caspase- 3 as compared to that in the cirrhotic group. Similarily, other researchers ${ }^{[31]}$ observed their antiapoptotic effect on the degenerating neurons in perinatal hypothyroidism model. They act on mitochondrial pathway via maintaining the anti-apoptotic balance of Bcl-2 family proteins. In addition, omega-3 fatty acids down-regulate phosphorylation of Jun-NH2 terminal kinase JNK; the direct targets for caspases in the induction and execution of apoptosis ${ }^{[32]}$. Morover, they regulates cell survival signaling proteins ${ }^{[33]}$. Besides, the antiapoptotic effect of omega-3 fatty acids proven to ameliorate formaldehyde stress effects on various tissues ${ }^{[34]}$. However, others ${ }^{[35]}$ demonstrated that omega-3 fatty acids induced apoptosis in cancer via Bax-dependent mitochondrial pathway. Thus, the antiapoptotic effect of omega-3 fatty acids is dependent on the surrounding microenvironmental condition.

In the current study, combined with the significant decrease in collagen fibers demonstrated in Masson trichrome stain (F2), there was a significant reduction in $\alpha$-SMA and TIMP-1 expression in group III as compared to that in group II. In line with our results, Zhang et al. $2016^{[36]}$ reported that omega-3 fatty acids down-regulate the expression of profibrogenic genes in activated HSCs by inducing degradation of their transcriptional regulator; Yes-associated protein (YAP) in a proteasome dependent manner. In addition, omega-3 fatty acids exerted a potent anti-fibrotic effect in the models of cardiac and pulmonary fibrosis $^{[37,38]}$.

In our current research, a significant reduction of CD68 positive macrophages in the connective tissue with significant increase in Kupffer cells were observed in group III as compared to that in group II. However, connective tissue macrophages significantly increased as compared to that in the control. Macrophages have a role both in liver fibrogenesis and fibrinolysis by acquiring different phenotypes. The most important phenotypes of macrophages are M1 (classically activated) and M2 (alternatively activated) ${ }^{[39]}$. Alike, Beljaars et al, 2014 found that during resolution of fibrosis macrophages, predominantly of M1 phenotype, increased matrix degradation via increased secretion of MMP-13 ${ }^{[24]}$. Furthermore, omega-3 fatty acids reduce inflammatory cytokines production by macrophages ${ }^{[40]}$.

In the present study, omega-3 fatty acids led to reduction of neoangiogenesis and loss of capillarization with significant decrease in CD31 expression as compared to that in group II. Previous reports ${ }^{[41]}$ confirmed the role of omega-3 in decreasing neoangeogenesis in tumors. This could be attributed to the anti-fibrotic and antiinflammatory roles of omega 3 fatty acids. In addition to the role of activated HSCs in collagen deposition in the basement membrane of the capillarized sinusoids, they release signals which stimulate dedifferentiation and loss of fenestrae in sinusoidal endothelium, vice versa, HSCs quiescence is promoted by differentiated sinusoidal endothelial cells ${ }^{[42]}$.

\section{CONCLUSION}

Omega- 3 fatty acids may be a promise for the treatment of liver cirrhosis. Further studies are recommended to prove the efficiency of omega-3 in clinical improvement of cirrhotic patients.

\section{CONFLICT OF INTEREST}

There are no conclicts of interest.

\section{REFERENCES}

1. Liedtke C, Luedde $\mathrm{T}$, Sauerbruch $\mathrm{T}$, et al. Experimental liver fibrosis research: update on animal models, legal issues and translational aspects. Fibrogenesis \& Tissue Repair2013; 6(19).

2. World Health Organization (WHO), 2017.

3. Elgharably A, Gomaa A I, Crossey M M, et al. Hepatitis C in Egypt - past, present, and future. International Journal of General Medicine 2017, 10, 1-6. 
4. Delire B, Stärkel P, Leclercq I. Animal models for fibrotic liver diseases: What we have, what we need, and what is under development. Journal of Clinical and Translational Hepatology 2015, 3(1), 53-66.

5. Friedman S L, Bansal M B. Reversal of hepatic fibrosis - fact or fantasy? Hepatology2006; 43(2 Suppl 1):S82-8.

6. Hardman WE. (n-3) Fatty acids and cancer therapy. J Nutr2004; 134: 3427-3430.

7. Aronson WJ, Glaspy JA, Reddy ST, et al. Modulation of omega-3/ omega- 6 polyunsaturated fatty acids ratios with dietary fish oils in men with prostate cancer. Urology 2001; 58: 283-288.

8. Din JN, Newby DE, Flapan AD. Omega-3 fatty acids and cardiovascular disease fishing for a natural treatment. Br Med J2004 ; 328: 330-335.

9. Young $\mathrm{C}$, Martin A. Omega-3 fatty acids in mood disorders. An overview. Rev Bras Psiquiatr 2003; 25: 184-187.

10. Iraz M1, Erdogan H, Ozyurt B, et al. Omega-3 essential fatty acid supplementation and erythrocyte oxidant/antioxidant status in rats. Ann Clin Lab Sci2005; 35: 169- 173.

11. Atakisi O, Atakisi E, Ozcan A, et al. Protective effect of omega-3 fatty acids on diethylnitrosamine toxicity in rats. Eur Rev Med Pharmacol Sci.2013;17(4):467-71.

12. Pastor-Clerigues A, Marti-Bonmati E, Milara $\mathrm{J}$, et al. Anti-Inflammatory and anti-fibrotic profile of fish oil emulsions used in parenteral nutrition-associated liver disease. PLos one $2014 ; 9(12)$ : e115404.

13. Vanheule E, Geerts AM, Huysse JV, et al. An intravital microscopic study of the hepatic microcirculation in cirrhotic mice models: relationship between fibrosis and angiogenesis. Int. J. Exp. Path. 2008 ;89, 419-432.

14. Abdelmegeed M A, Choi Y, Godlewski G, et al. Cytochrome P4502-E1 promotes fast food-mediated hepatic fibrosis. Scientific Reports 2017; 7: 39764.

15. Bancroft J D, Layton C, Suvarna S K. Bancroft's theory and practice of histological techniques 2013, 7th edition, Oxford: Churchill Livingstone Elsevier.
16. Bedossa P, Poynard T. An algorithm for the grading of activity in chronic hepatitis C. The METAVIR Cooperative Study Group. Hepatology 1996;24; 289-293.

17. Li Z, Wei W, Chen B1, et al. The Effect of rhCygb on CCl4-induced hepatic fibrogenesis in Rat. Sci Rep. 2016;23:508.

18. Guo XL, Liang B, Wang XW, et al. Glycyrrhizic acid attenuates $\mathrm{CCl} 4$-induced hepatocyte apoptosis in rats via a p53-mediated pathway. World J Gastroenterol 2013 ; 19(24): 3781-3791.

19. Tousson E, Ali E.M, Moustafa AA, et al. Proliferating Cell Nuclear Antigen as A Biomarker for Thioacetamide Induced Hepatotoxicity of Rat Liver. American Journal of Zoological Research 2014; 2( 3):51-54.

20. Zaki MM, Ataa HM, Shenouda HD, et al. Effect of mesenchymal stem cells administered by two different routes on experimentally induced liver fibrosis in rats. Egypt J Histol 2011; 34: 780-789.

21. Wang H, Lafdil F, Wang L, et al. Tissue inhibitor of metalloproteinase 1 (TIMP-1) deficiency exacerbates carbon tetrachloride-induced liver injury and fibrosis in mice: involvement of hepatocyte STAT3 in TIMP-1 production. Cell Biosci 2011; 14:1.

22. Robert S, GicquelT, Bodin A, et al. Characterization of the MMP/TIMP Imbalance and Collagen Production Induced by IL- $1 \beta$ or TNF- $\alpha$ Release from Human Hepatic Stellate Cells. PLoS ONE 2016;11(4): e0153118.

23. Mori Y, Izawa T, Takenaka S, et al. Participation of functionally different macrophage populations and monocyte chemoattractant protein-1 in early stages of thioacetamide-induced rat hepatic injury. Toxicol Pathol. 2009; 37(4):463-73.

24. Beljaars L, Schippers M, Reker-Smit C, et al. Hepatic localization of macrophage phenotypes during fibrogenesis and resolution offibrosis in mice and humans .Frontiers in Immunology2014;5:430

25. MacPhee PJ, Schmidt EE, Groom AC. Evidence for Kupffer cell migration along liver sinusoids, from high-resolution in vivo microscopy Am J Physiol.1992.; 263 (1 Pt 1):G17-23.

26. Bocca C, Novo E, Miglietta A et al. Angiogenesis and fibrogenesis in chronic liver diseases. Cell Mol Gastroenterol Hepatol. 2015; 1(5): 477-488. 
27. DeLeve L. liver sinusoidal endothelial cells in hepatic fibrosis Hepatology2015; 61(5): 1740-1746.

28. Carvalho C, Santos RX, Cardoso S, et al. Doxorubicin: the good, the bad and the ugly effect. Curr Med Chem2009; 16:3267 - 3285.

29. Uygur R, Aktas C, Tulubas F, et al. Protective effects of fish omega-3 fatty acids on doxorubicininduced testicular apoptosis and oxidative damage in rats. Andrologia. 2014;46 (8): 917-26.

30. Chen F, Liu Y, Zhu H, et al. Fish oil attenuates liver injury caused by LPS in weaned pigs associated with inhibition of TLR4 and nucleotidebinding oligomerization domain protein signaling pathways. Gastroenterology2013; 142: 918-927.

31. Sinha RA, Khare P, Rai A, et al. Anti-apoptotic role of omega-3-fatty acids in developing brain: perinatal hypothyroid rat cerebellum as apoptotic model. Int J Dev Neurosci. 2009;27(4): 377-83.

32. Cross TG, Scheel-Toellner D, Henriquez $\mathrm{N} \mathrm{V}$, et al. Serine/threonine protein kinases and apoptosis. Exp. Cell Res. 2000; 256: 34-41.

33. Mukherjee PK, Chawla A, Loayza M.S et al. Docosanoids are multifunctional regulators of neural cell integrity and fate: significance in aging and disease. Prostaglandins Leukot. Essent. Fatty Acids 2007;77: 233-238.

34. Zararsiz I, Sonmez MF, Yilmaz HR, et al. Effects of omega-3 essential fatty acids against formaldehyde-induced nephropathy in rats. Toxicol Ind Health. 2006;22(5): 223-9.

35. Granci V, Cai F, Lecumberri E, et al. Colon cancer cell chemosensitisation by fish oil emulsion involves apoptotic mitochondria pathway. $\mathrm{Br} \mathrm{J}$ Nutr. 2013;109(7):1188-95.

36. Zhang K, Chang Y, Shi Z, et al. $\omega-3$ PUFAs ameliorate liver fibrosis and inhibit hepatic stellate cells proliferation and activation by promoting YAP/TAZ degradation. Sci Rep. 2016;20(6):30029.

37. Chen J, Shearer GC, Chen Q, et al. Omega-3 fatty acids prevent pressure overload-induced cardiac fibrosis through activation of cyclic GMP/ protein kinase $\mathrm{G}$ signaling in cardiac fibroblasts. Circulation2011;123(6): 584-93.

38. Zhao H, Chan-Li Y, Collins SL, et al. Pulmonary delivery of docosahexaenoic acid mitigates bleomycin-induced pulmonary fibrosis. BMC Pulm Med. 2014;(18)14: 64.

39. Fallowfield JA, Mizuno M, Kendall TJ, et al. Scar-associated macrophages are a major source of hepatic matrix metalloproteinase-13 and facilitate the resolution of murine hepatic fibrosis. J Immunol (2007) ;178(8):5288-95.

40. Walter KR, Xi L, Jacobi SK, et al. Dietary Long-chain PUFAs Enrich Porcine Alveolar Macrophages and Alter Prostaglandin E2 Production Following LPS Challenge FASEB J2017; 31:964.12

41. Taguchi A, Kawana K, Tomio K, et al. Matrix metalloproteinase (MMP)-9 in cancer-associated fibroblasts (CAFs) is suppressed by omega-3 polyunsaturated fatty acids in vitro and in vivo. PLos One 2014;9(2):e89605.

42. Xie G, Wang X, Wang L, et al. Role of liver sinusoidal endothelial cell differentiation in progression and regression of rat hepatic fibrosis. Innate Immun. 2012;19(5):5041- 
الملخص العربى

تأثير الأحماض الدهنية أوميجا- 3 على تطور التّليف الكبدى المسبب برباعى كلوريد الكربون في

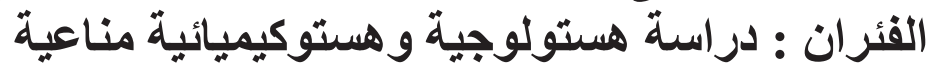

ايمان السيد ابوضيف1، ضحى صابر محمد1، نسرين جمال الاين عبد الحليم، شيرين أحمد محمد1، أشرف محمد البلرى فيرين جمال

1قسم الهستولوجى، 2قسم الجراحة كلية طب سوهاج، سوهاج، مصر

المقدمة: يعتبر تليف الكبد نتيجة نهائية لالتهابات الكبد المزمنة ويظهر في صورة تز ايد في النسيج الليفى بالكبد وتغير الهيكل

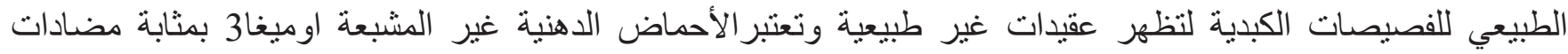

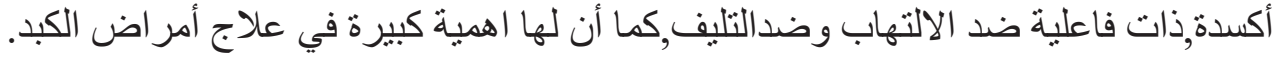

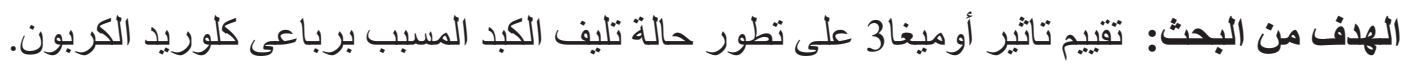

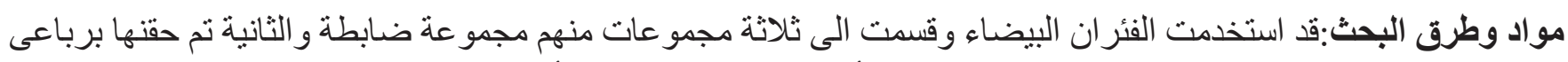

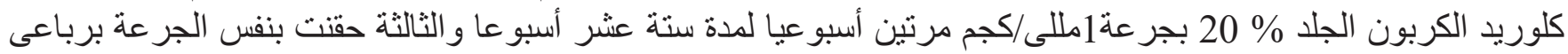

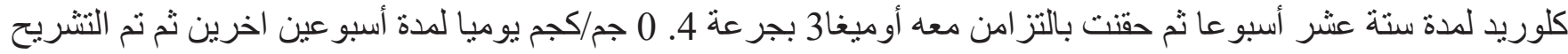
للحصول على عينة الكبد بعد 48 ساعة.

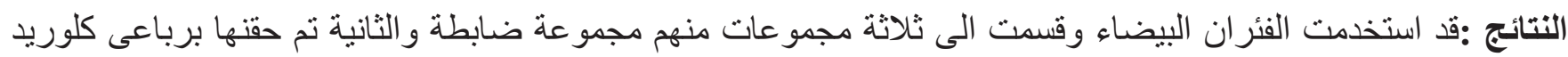

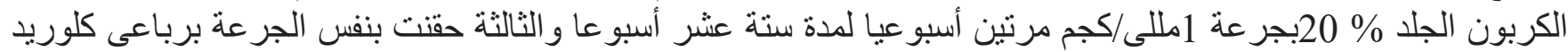

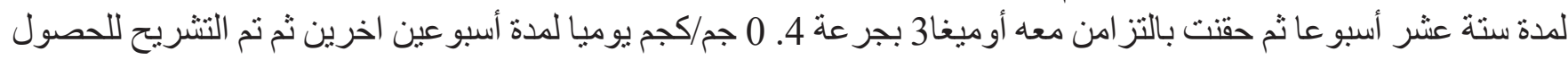
على عينة الكبد بعد 48 ساعة. الإستنتاج : لاستخدام أوميغا3 38 تأثنير ملحوظ في تحسن التليف الكبدي فى الفئران البيضاء ومن ثم يمكن در استه اكلينيكيا على بعض حالات التليف الكبدى فى الانسان. 